\title{
GENETIC DIVERSITY OF INDIGOFERA KIRILOWII MAXIM. EX PALIBIN USING AFLP MAKERS
}

\author{
Qikui Wu', Limin Sun, XiaOjing LiU, Xuan Wang, Xia Sun ${ }^{2 *}$ \\ AND ShIYAN XING* \\ Key Laboratory of Silviculture in Shandong Province, College of Forestry, \\ Shandong Agricultural University, Tai'an, Shandong 271000, China
}

Key words: Genetic structure, Genetic relationships, Conservation strategy

\begin{abstract}
The present studies were conducted to assess the genetic diversity and to infer population structure of 220 individuals of Indigofera kirilowii from 8 natural populations of Shandong province, north China, using amplified fragment length polymorphism (AFLP) markers. A total of 1589 AFLP bands were produced, of which $99.87 \%$ were polymorphic. High genetic diversity was considered $(H=0.1401 ; I=0.2346)$, with high genetic differentiation $\left(G_{S T}=0.1058\right)$, while estimates of gene flow $\left(N_{m}\right)$ were high in all analysis. No correlations were observed between geographic location and genetic diversity $(\mathrm{r}=-0.0901 ; \mathrm{p}=0.3293)$. Based on the results, here a strategy for the conservation of $I$. kirilowii germplasm was proposed.
\end{abstract}

Indigofera kirilowii Maxim. ex Palibin is one of the native tree species with important medicinal and landscaping value, which mainly distributes in the northeast and north China. Previous studies on I. kirilowii are only limited in chromosome (Wang and Xu 1994), chemical constituents (Su et al. 2006, Lv et al. 2009, seedling cultivation (Deng et al. 2008), seeds germination (Zhao et al. 2013), urban landscaping (Ji 2011) and comprehensive utilization (Xu et al. 2016). However, no research about the genetic diversity and population structure of $I$. Kirilowii has been reported. Assessment of genetic diversity and population structure of the species is of the great necessity for utilization and protect I. kirilowii resources. Because of environmental destruction by human disturbance and over development caused a sharp decline in natural populations of I. kirilowii. Therefore, it is very necessary to take some adoption of effective conservation strategy for this species.

Amplified fragment length polymorphism (AFLP) is a kind of quite effective molecular marker technique, which has been widely applied in assessing the genetic diversity and population structure among endangered species (Vos et al. 1995, Cires et al. 2013). AFLP markers were applied in this study to assess the genetic diversity and population structure of $220 \mathrm{I}$. kirilowii germplasms from 8 different populations to provide certain theoretical evidences for utilization and conservation of natural $I$. kirilowii resources.

Young leaves were collected from $220 \mathrm{I}$. kirilowii individuals from 8 different populations of Shandong province, north China. The geographic locations of sampling sites are shown in Fig.1, and the details are presented in Table1. The number of samples per populations varied from 8 to 54. The collected leaves were stored with silica gel in zip-lock bags until DNA extraction. Total genomic DNA was extracted from dried leaf tissues following the modified Doyle (1987) CTAB method. All the experimental operations were carried out in key laboratory of silviculture in Shandong province, Tai'an.

\footnotetext{
* Author for correspondence: <sunxia65@sina.com>. ${ }^{1}$ Collaborative Innovation Centre of Sustainable Forestry in Southern China, College of Forest Science, Nanjing Forestry University, Nanjing-210037, China. ${ }^{2}$ College of Horticulture Science and Engineering, Shandong Agriculture University, Tai'an-271000, China.
} 
AFLP analysis was carried out by a justified protocol described by Vos et al. (1995). In brief, genomic DNA was digested with Pst I and MseI restriction endonucleases. Eight primer combinations with high and stable polymorphism selected from 64 combinations were employed for the generation of markers: P-GAC/M-CAA, P-GAC/M-CAC, P-GAG/M-CAA, P-GAG/M-CAG, $P$-GAG/M-CTT, P-GTG/M-CAA, P-GTG/M-CTA, and P-GTG/M-CTG, where $P$ represents 5'GACTGCGTACATGCA-3' and $M$ represents 5'-GATGAGTCCTGAGTAA-3'. AFLP data were generated using Gene Mapper software of ABI PRISM 37 DNA sequence and scored as "1" (presence of fragment) and "0" (absence of fragment). The genetic diversity parameters (Wang et al. 2015) were computed using POPGENE v.1.31 (Yeh and Boyle 1997). Two cluster analysis using the unweighted pair group method of arithmetic averages (UPGMA) were performed with the program NTSYS-pc2.10e (Rohlf 1987): a population level analysis based in $I_{n}$, and an analysis of individuals based on Dice's similarity coefficient. The mantel test of the genetic and geographical distance correlation was calculated using NTSYS-pc2.10e.

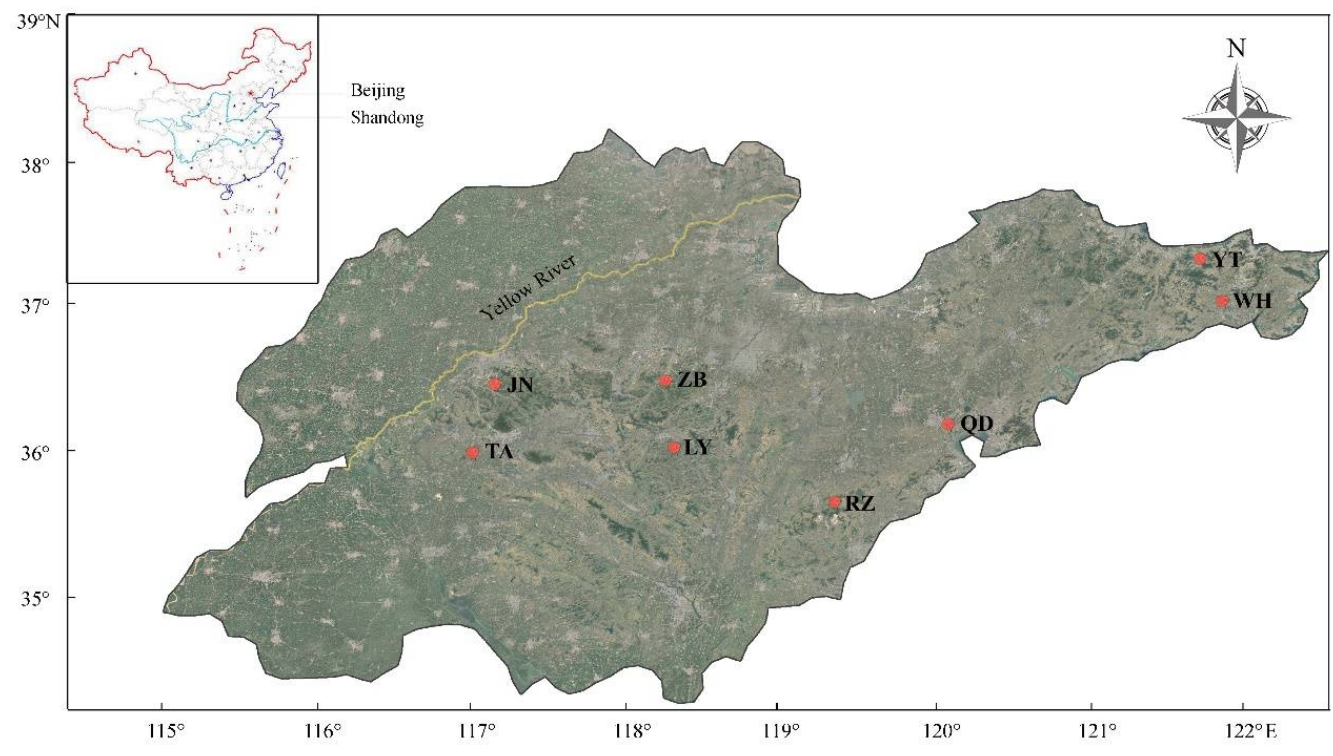

Fig. 1. Geographic location of the eight sampled I kirilowii populations in Shandong province, China. JN = Jinan; LY = Linyi; QD = Qingdao; RZ = Rizhao; TA = Tai'an; WH = Weihai; YT = Yantai and ZB = Zibo.

Eight primer combinations with clear bands, strong polymorphism and favourable repeatability were selected from 64 combinations to evaluate and characterize the 220 sampled $I$. kirilowii individuals. These primers generated 1589 bands, of which 1587 (99.87\%) were polymorphic (Table 1), showing that the I. kirilowii exhibited a high level of polymorphism. The number of polymorphic bands per population ranged from 85 (43.05\%) in RZ to 149 (75.05\%) in TA, with an average of 198 (58.25\%). Overall, genetic diversity $(H)$ and Shannon's information index $(I)$ reached 0.1401 and 0.2346 at the special level respectively, with an average of 0.1238 and 0.2000 at the population level. The genetic diversity values found in this study were similar to other studies based on AFLP markers which focused on endangered species in Shandong province, north China (Wang et al. 2012, Wang et al. 2015). The analysis of correlation indicates 
that genetic diversity was significantly influenced by the population size $(r=0.916)$, since the large populations exhibited higher genetic diversity value $(H)$ compared with small populations. Among the 8 analysed populations, TA was the highest genetic diversity $(H=0.1487)$, while QD was the lowest one $(H=0.1039)$, which may be related to the different growth situations of these two populations. The individuals of population TA were thriving, which may maintain more genetic diversity. However, the population QD has been damaged by human disturbance and over development, which may be an important factor for resulting in low genetic diversity.

Table 1. Details of sampling locations and genetic diversity of I. kirilowii germplasm.

\begin{tabular}{lccccccc}
\hline Population & $\begin{array}{c}\text { Latitude } \\
(\mathrm{N})\end{array}$ & $\begin{array}{c}\text { Longitude } \\
(\mathrm{E})\end{array}$ & $\begin{array}{c}\text { Elevation } \\
(\mathrm{m})\end{array}$ & $\mathrm{S}$ & $P(\%)$ & $H$ & $I$ \\
\hline JN & $36^{\circ} 29^{\prime}$ & $117^{\circ} 03^{\prime}$ & 376 & 22 & $113(56.94)$ & $0.1258 \pm 0.1650$ & $0.2020 \pm 0.2381$ \\
LY & $36^{\circ} 03^{\prime}$ & $118^{\circ} 26^{\prime}$ & 418 & 30 & $125(63.05)$ & $0.1252 \pm 0.1607$ & $0.2042 \pm 0.2306$ \\
QD & $36^{\circ} 12^{\prime}$ & $120^{\circ} 07^{\prime}$ & 345 & 16 & $86(43.33)$ & $0.1039 \pm 0.1574$ & $0.1658 \pm 0.2310$ \\
RZ & $35^{\circ} 41^{\prime}$ & $19^{\circ} 20^{\prime}$ & 467 & 8 & $85(43.05)$ & $0.1178 \pm 0.1642$ & $0.1858 \pm 0.2415$ \\
TA & $36^{\circ} 01^{\prime}$ & $116^{\circ} 54^{\prime}$ & 462 & 37 & $149(75.05)$ & $0.1487 \pm 0.1650$ & $0.2426 \pm 0.2323$ \\
WH & $37^{\circ} 02^{\prime}$ & $121^{\circ} 57^{\prime}$ & 325 & 35 & $125(62.75)$ & $0.1226 \pm 0.1608$ & $0.1994 \pm 0.2313$ \\
YT & $37^{\circ} 18^{\prime}$ & $121^{\circ} 48^{\prime}$ & 387 & 54 & $146(73.46)$ & $0.1325 \pm 0.1575$ & $0.2186 \pm 0.2254$ \\
ZB & $36^{\circ} 30^{\prime}$ & $118^{\circ} 12^{\prime}$ & 389 & 18 & $96(48.37)$ & $0.1137 \pm 0.1610$ & $0.1819 \pm 0.2350$ \\
Average & & & & - & $115(58.25)$ & $0.1238 \pm 0.1615$ & $0.2000 \pm 0.2332$ \\
Species level & & & & 220 & $1598(99.87)$ & $0.1401 \pm 0.1574$ & $0.2346 \pm 0.2192$ \\
\hline
\end{tabular}

$\mathrm{S}$, samples size; $P$, polymorphic bands; $H$, Nei's gene diversity; $I$, Shannon's information index.

The mean overall genetic diversity $\left(H_{T}\right)$ of the eight population and the mean genetic diversity within populations $\left(H_{S}\right)$ were 0.1385 and 0.1238 , respectively. The mean coefficient value of genetic differentiation among populations $\left(G_{S T}\right)$ was 0.1058 , which indicates that the genetic variations within and among populations were $89.42 \%$ and $10.58 \%$, respectively. Gene flow was one of the important factors which influenced the degree of genetic variation among natural plant population, and the average gene flow value of hybrid species is 3.5 (Levin and Kerster 1974, Chen 1996). Populations with higher gene flow tended to have lower genetic differentiation. The estimated extent of gene flow $\left(N_{m}\right)$ among populations was 4.2904 based on the measured $G_{S T}$ values, which suggested the existence of strong gene exchange among populations. The mixedmating system may serve as an important factor that affects the population differentiation of $I$. kirilowii.

The genetic similarity coefficient between 220 I. kirilowii germplasm ranged from 0.1879 (between LY07 and LY08) to 0.8328 (between WH09 and TA21), with an average of 0.5528. Among populations, Nei's unbiased genetic identity $\left(I_{n}\right)$ ranged from 0.9750 (between QD and ZB) to 0.9932 (between WH and YT), with an average of 0.9844 . The genetic distance of the eight populations ranged from 0.0068 (between WH and YT) to 0.0254 (between QD and ZB), with an average of 0.0158 (Table 2). A UPGMA dendrogram of genetic relationship among the eight populations was constructed based on Nei's genetic distance. As shown in the dendrogram in Fig.2, populations WH and YT with nearest geographical distance $(33.89 \mathrm{~km})$ between them were grouped into a cluster firstly, then gathered together with populations JN, TA, LY, RZ, and finally with populations $\mathrm{ZB}$ and $\mathrm{QD}$. However, for populations $\mathrm{TA}$ and $\mathrm{WH}$, despite the farthest geographical distance $(466.33 \mathrm{~km})$ between them, their genetic distance was not the largest. This suggested that genetic distance was not strictly related to geographic distance among these eight 
populations (Wang et al. 2015). The Mantel's test revealed no correlation between genetic differentiation and geographic distance $(r=-0.0901 ; p=0.3293)$.

Table 2. Pairwise geographical distance (in $\mathbf{~ k m}$ ) and genetic distance between eight populations of $I$. kirilowii (above and below diagonals, respectively).

\begin{tabular}{lcccccccc}
\hline Population & JN & LY & QD & RZ & TA & WH & YT & ZB \\
\hline JN & $* * * *$ & 118.68 & 276.00 & 223.99 & 52.95 & 442.13 & 433.67 & 102.94 \\
LY & 0.0123 & $* * * *$ & 167.28 & 105.34 & 333.07 & 348.41 & 346.55 & 50.38 \\
QD & 0.0227 & 0.0202 & $* * * *$ & 90.36 & 289.43 & 188.81 & 194.88 & 174.25 \\
RZ & 0.0178 & 0.0117 & 0.0225 & $* * * *$ & 223.19 & 278.22 & 285.24 & 136.55 \\
TA & 0.0118 & 0.0120 & 0.0245 & 0.0160 & $* * * *$ & 466.33 & 461.28 & 128.34 \\
WH & 0.0174 & 0.0132 & 0.0181 & 0.0148 & 0.0144 & $* * * *$ & 33.89 & 340.73 \\
YT & 0.0119 & 0.0113 & 0.0134 & 0.0123 & 0.0109 & 0.0068 & $* * * *$ & 333.73 \\
ZB & 0.0148 & 0.0171 & 0.0254 & 0.0187 & 0.0178 & 0.0183 & 0.0141 & $* * * *$ \\
\hline
\end{tabular}

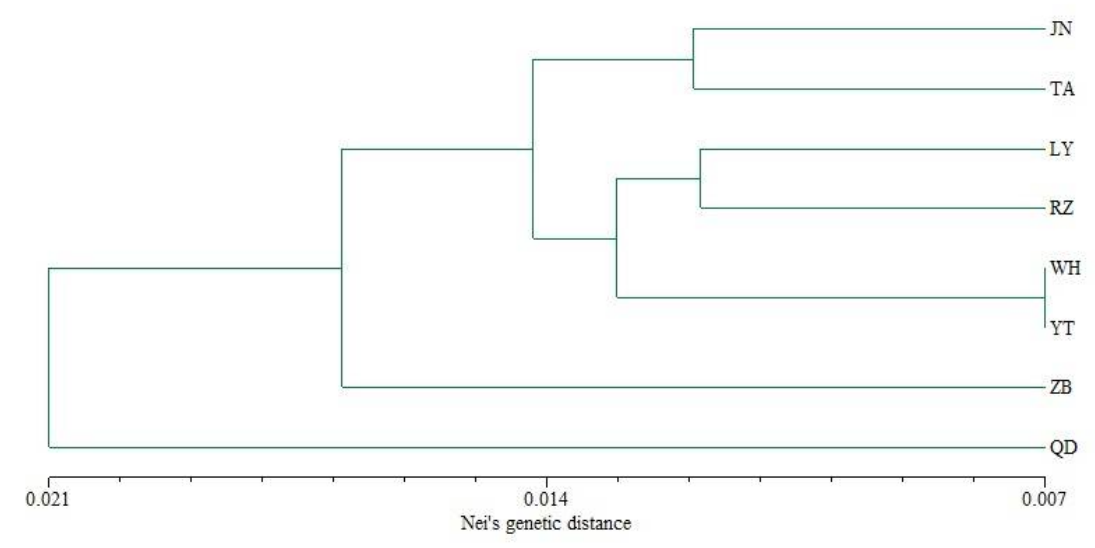

Fig. 2. UPGMA dendrogram of I. kirilowii populations based on AFLP data.

The utilities of genetic diversity analysis by AFLP markers in wild plant species conservation were widely reported (Wu et al. 2014, Wang et al. 2015 and Silva et al. 2016). Maintaining genetic variation is the major objective and guide in endangered species conservation plans (Schaal et al. 1991, Avise and Hamrick 1996). This study showed that I. kirilowii maintained relatively high genetic diversity, and our field survey revealed that the reason for the endangered status of I. kirilowii may be human disturbance and over development, rather than the lack of overall genetic diversity (Yang et al. 2016). So, in situ conservation measures are supposed to be adopted firstly. Some populations with more abundant germplasm resources, e.g. TA and YT, should be given high priority in in situ conservation. Meanwhile, some populations with weak growth and low polymorphism level, e.g. QD and RZ, should be expanded and updated by artificial cultivation, with individuals or offspring from populations TA and YT properly introduced to increase genetic diversity.

\section{Acknowledgments}

We are grateful to Lipeng Zang, Yanhui Zhang and Qianqian Kong for their indispensable assistance in the field and laboratory work. The authors are thankful to the Agricultural Breeding Project of Shandong Province ([2011]7) for financial support. 


\section{References}

Avise JC and Hamrick JL 1996. Conservation Genetics: Case Histories from Nature. New York: Chapman and Hall. pp. 510-512.

Chen XY 1996. Plant gene flow and its role in protect endangered plants. Biodivers. Sci. 4(2): 97-102.

Cires E, Cuesta C and Fernández PJA 2013. Genetic diversity and structure in fragmented populations of the endangered species Ranunculus cabrerensis (Ranunculaceae): implications for conservation. Biologia. 68(1): $30-40$.

Deng JY, Jiang YX and Li CZ 2008. Studies on the vegetative propagation of Indigofera Kirilowii. Pra. For. Te. 1: 23-24.

Doyle JJ 1987. A rapid DNA isolation procedure for small quantities of fresh leaf tissue. Phyt. Bull. 19(1): 11-15.

Ji YW 2011. Investigation and planning of urban landscaping greening trees species of Hebei Province. Hebei Agriculture University. pp. 22-26.

Levin DA and Kerster HW 1974. Gene flow in seed plants. Evol. Biol. 7: 139-220.

Lv M, Su YF, Gao Y, Song DB, Gao XM and Zhang BL 2009. Chemical constituents in two species of Indigofera Linn. Chin. Tradit. Herb. Drugs. 40(3): 356-360.

Rohlf F J 1987. NTSYS-pc: Microcomputer Programs for Numerical Taxonomy and Multivariate Analysis. Am. Stat. 41(4): 330-330.

Schaal BA, Leverich WJ and Rogstad SH 1991. Comparison of methods for assessing genetic variation in plant conservation biology. In: Falk DA and Holsinger KE (Eds.), Genetics and Conservation of Rare Plants. New York: Oxford University Press. pp: 123-134.

Silva LND, Essi L, Welke CAD and Souza-Chies TTD 2016. Assessing the genetic diversity and population structure of the endangered Chascolytrum bulbosum (Poaceae, Poeae) using AFLP markers. Biochem. Syst. Ecol. 68: 236-242.

Su YF, Yang Y, Fan W, Lv M, Guo ZJ, and Lv JX 2006. Chemical constituents of Indigofera kirilowii stems and leaves. Chin. Tradit. Herb. Drugs. 37(12): 1775-1777.

Vos P, Hogers R, Bleeker M, Reijans M, T Lee, Hornes M, Friters A, Pot J, Paleman J, Kuiper M and Zabeau M 1995. AFLP: a new technique for DNA fingerprinting. Nucleic Acids Res. 23(21): 4407-4414.

Wang B and Xu XJ 1994. Studies on the chromosome of Indigofera Kirilowii. J. Chin. Med. Mat. 17(1): 3-4.

Wang DS, Zhou JL, Jie HF, Xing SY, Li JH, Wang W and Sun BY 2012. AFLP genetic diversity analysis of Robinia pseudoacacia clones. J. Southwest For. Uni. 32(6): 25-29.

Wang X, Xing SY, Sun LM, Liu XJ and Kong QQ 2015. Genetic diversity of Styrax obassia Sieb. et Zucc. based on AFLP markers. Biochem. Syst. Ecol. 61: 28-34.

Wu QK, Xing SY, Wang X and Sun LM 2014. Genetic diversity of leaf-used Ginkgo biloba germplasms based on flavonoids and ginkgolides contents and AFLP markers. Acta Hortic. Sinica. 41(12): 23732382.

Xu XY, Chui L, Zhang YZ and Wang LG 2016. Studies on cultivation techniques and comprehensive utilization of Indigofera Kirilowii. Modern Agr. Sci. Tec. 23: 49-50.

Yang HS, Li XP, Liu DJ, Chen XB, Li FH, Qi XL, Luo ZW and Wang CB 2016. Genetic diversity and population structure of the endangered medicinal plant Phellodendron amurense in China revealed by SSR markers. Biochem. Syst. Ecol. 66: 286-292.

Yeh FC and Boyle TJB 1997. Population genetic analysis of codominant and dominant markers and quantitative traits. Belg. J. Bot. 129: 157-163.

Zhao JT, Liu QC, Wang KL and Liu QH 2013. Studies on characteristics of hard seeds and germination of Indigofera kirilowii. Seed. 12: 23-26.

(Manuscript received on 10 February, 2018; revised on 27 July, 2019) 